\title{
Adjustment of Stresses in the Top Chord of the Dome-Like Hybrid Roof Structure
}

\author{
A.V. Chesnokov", V.V. Mikhailov ${ }^{\vee}$, I.V. Dolmatov ${ }^{\star}$ \\ * The Faculty of Civil Engineering \\ Lipetsk State Technical University \\ Moskovskaya street 30, 398600 Lipetsk, Russian Federation \\ e-mail: andreychess742@gmail.com,web page: http://www.stu.lipetsk.ru \\ $\checkmark$ The Faculty of Civil Engineering \\ Lipetsk State Technical University \\ Moskovskaya street 30, 398600 Lipetsk, Russian Federation \\ e-mail:mmvv46@rambler.ru, web page: http://www.stu.lipetsk.ru \\ - The Faculty of Civil Engineering \\ Lipetsk State Technical University \\ Moskovskaya street 30, 398600 Lipetsk, Russian Federation \\ e-mail: dolmivv@gmail.com, web page: http://www.stu.lipetsk.ru
}

\begin{abstract}
The roof, considered in the research, includes rigid beams, steel cables, hinged struts and a polymer membrane shell [1]. The beams are arranged in the radial direction forming the top chord of the roof, while the cables and the struts compose the bottom chord. Polymer membrane is attached to the beams and pre-tensioned by backstay cables.

Non-uniform impacts, e.g. snow load on a half of the span, adversely affect on the roof structure, resulting in significant increase in stress in the beams. Spatial ribs and additional ties effectively mitigate bending moments in the beams [1]. The drawback is in substantial complication of the construction.
\end{abstract}

To reduce material consumption under various external influences so-called 'adaptable' structures have emerged [2]. The adaptation is an additional targeted influence on the structure, which diminishes adverse factors caused by external impacts.

The present study investigates adjustment of backstay cables tensioning for diminishing stresses in the hybrid roof, made of flat ribs. Separate and simultaneous adjustment strategies are examined. The first strategy reduces bending moments in particular beams only. It brings about overall increase in stress and, thus, can not be adopted.

Simultaneous cable adjustment task is converted into an optimization problem for stress reduction. Coordinate descent method is considered for obtaining appropriate cable tensioning. Simultaneous cable adjustment allows to apply the hybrid roof composed of 'flat ribs', instead of complicated spatial structure.

The results of the work contribute to the improvement of hybrid constructions, which are prospective for public and industrial buildings, as well as in developing remote territories with harsh climatic conditions.

\section{REFERENCES}

[1] A.V. Chesnokov, V.V. Mikhailov and I.V. Dolmatov, "Development of the hybrid dome and research of its behavior under load", Structural Membranes 2015. Proc. of the VII International Conference on Textile Composites and Inflatable Structures. P. 469 - 476 (2015). http://congress.cimne.com/membranes2015/frontal/doc/Ebook2015.pdf

[2] A. Habraken, W. Sleddens and P. Teuffel, "Adaptable lightweight structures to minimize material use", Structural Membranes 2013. Proc. of the VI International Conference on Textile Composites and Inflatable Structures. P. 71-82 (2013). 